\title{
Stress Raisers and Its Effect on Fatigue Sensitivity: A Study of Notch and Fretting Fatigue
}

\author{
M.A. Rahmat ${ }^{1, *}$, R.N. Ibrahim ${ }^{1}$, R.H. Oskouei ${ }^{2}$ \\ ${ }^{1}$ Department of Mechanical \& Aerospace Engineering, Monash University, Clayton, VIC 3800, Australia \\ ${ }^{2}$ School of Computer Science, Engineering \& Mathematics, Flinders University, Bedford Park, SA 5042, Australia \\ *Corresponding Author: mohamed.rahmat@monash.edu
}

Copyright (C) 2013 Horizon Research Publishing All rights reserved.

\begin{abstract}
In this study, stress raisers (notches, fretting fatigue and a combination of notch and fretting) were taken into consideration as to its performance in reducing fatigue life. Reduction factor measurements using fatigue sensitivity, $q$ as an effect of the respective stress raiser on fatigue lives were done. Finite element analyses on the consequence of clamping pressure on a notched geometry revealed a further increase in stress concentration at the notch tip for this specific geometry. However, fatigue tests revealed no significant difference in the fatigue lives between the notched and the combined notch and fretting fatigue. Fatigue notch sensitivity, $q_{n}$ was found to be between 0.42 and 0.65 while a fretting notch-like sensitivity, $q_{f}$ calculated from fretting fatigue results using a method by Wharton et al were 3.52 and 3.28 at torque levels $20 \mathrm{Nm}$ and $50 \mathrm{Nm}$ respectively. It was found that the stress concentration factor, $k_{t}$ for the fretting condition was conservative in its value and did not correlate well with the actual fretting reduction factor, $k_{f}$. Finally, fractorgraphic analysis revealed significant wear for both fretting fatigue specimens and the combined notch and fretting fatigue. However, cracks were only found to originate from the notch tip for the combined notch and fretting fatigue at all alternating stress levels.
\end{abstract}

Keywords Fatigue, Stress raiser, Notch Sensitivity, Fretting Fatigue

\section{Introduction}

It is imperative that structures that experience cyclic loading have its stress flow distribution studied. This case has been well defined in some well reputed texts but further emphasis is never in abundance. The argument of structural integrity in cases where cyclic loading is present will always be centered on the surface condition of the structure. This is because structural fatigue, a failure method that is dependent on localised stress raisers to initiate crack, will always occur at the surface of the material.

In this study, two different 'stress raisers' and a combination of the two are taken into consideration as to its performance in reducing fatigue life. The first 'stress raiser' is a typical notch [1]. Notches are notorious for influencing the stress distribution in producing high localised stresses. This factor, known simply as the theoretical stress concentration factor, $k_{t}$ is one of importance as its localised stress raiser is known to increase the applied force at the concentrated region, sometimes to a height above the crack opening threshold stress, thus expediting fatigue crack initiation. The other 'stress raiser' originates from wear and wear induced regions known as fretting fatigue [2]. Significant fretting problems have been seen to be greatly influenced by two mechanical parameters; (a) contact pressure, and (b) frictional force. While contact pressure is a parameter that is dependent on the contact condition and is therefore not in the control of the actual material experiencing fretting, frictional force as a parameter on the other hand can be modified by improving the surface conditions. Surface modifications such as the application of PVD coatings have been proven to have the ability to mitigate fretting wear and fretting fatigue for various applications [2-8]. This is because has been reported that there are at least five different mechanisms in using surface modification methods that were found to assist in improving fretting resistance: (1) introducing residual compressive stresses; (2) decreasing friction coefficient; (3) increasing surface hardness; (4) altering surface chemistry; (5) increasing surface roughness [6].

The more dominant failure mode between the two as well as its beneficial/detrimental relationship in initiating fatigue crack which leads to total failure needs to be examined. An example of such can be seen in the figure below which shows a cross section of a steel shaft on to which was keyed a cast iron wheel. It can be seen that fretting fatigue crack initiated, not at the point of stress concentration of the corner of the keyway, but somewhat higher up the side of the slot where the fretting scar had developed. This emphasises a point; that fretting can override the geometric stress concentrations present, and an analysis of a number of cases has suggested that fretting has an equivalent effect to a notch with a theoretical stress concentration factor $\left(k_{t}\right)$ equal to 4 [2]. 




Figure 1. Example cross section of steel shaft with combined stresses from stress concentrated corner and fretting due to perpetual sliding. Failure occurred region of fretting wear, ignoring the stress concentration at the corner [2]

Drawing parallels between notch fatigue and fretting fatigue in the context of recognising the initial crack phase can be seen when comparing a typical frictional contact stress state where the edge of the contact region often experiences a concentrated point load, much like the tip of a notch [9-14].

The purpose of this study is to assess the fatigue performance of fatigue specimens in the presence of stress raisers (notches, fretting, and a combination of notch and fretting) that would traditionally encourage early fatigue cracks to occur. High clamping forces present in the fretting fatigue test is intended to create a fretting wear region would assist in determining the effect of the fatigue resistance in such a situation. Measurements of the reduction factor using fatigue sensitivity, $q$ would be done using the well known equation:

$$
q=\frac{k_{f}-1}{k_{t}-1}
$$

Where $k_{t}$ is defined as the theoretical stress concentration factor as an effect of the stress raised from the change in geometry (notch) or additional stresses due to clamping pressure and friction (fretting) or a combination of both, and $k_{f}$ represents the actual fatigue notch (or 'notch-like' due to fretting) factor experimentally determined from the plotted $S-N$ curves. Fractographic analysis of fractured surfaces to determine the mode of failure was also done.

\section{Experimental Setup}

\subsection{Fatigue Specimens}

Two different round bar fatigue specimens were designed; smooth and notched specimens, as shown in Figure 2. The material for the specimen was a Böhler M200 which is a variation of the AISI P20 tool steel with chromium, manganese, and molybdenum as well as added sulphur for better machinability. The material was supplied by Böhler-Uddeholm Australia in a $50 \mathrm{~mm} \times 12 \mathrm{~mm}$ x 4000 $\mathrm{mm}$ rolled sheet. The element chemical composition for the alloy is listed in Table 1.

(a)
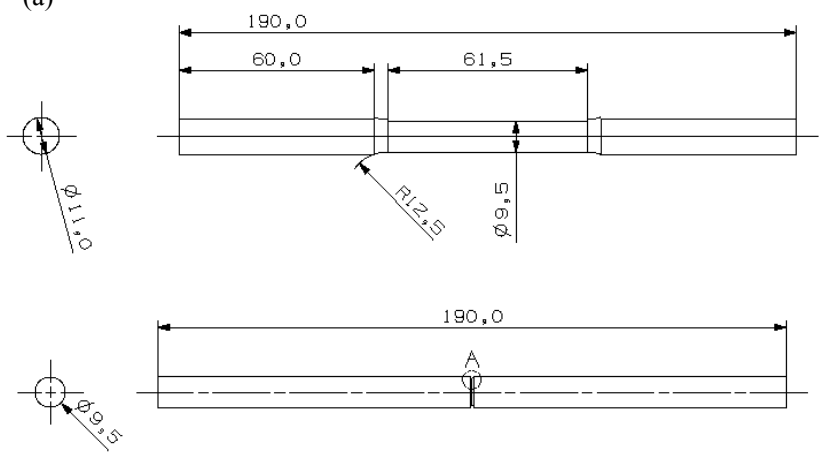

(b)

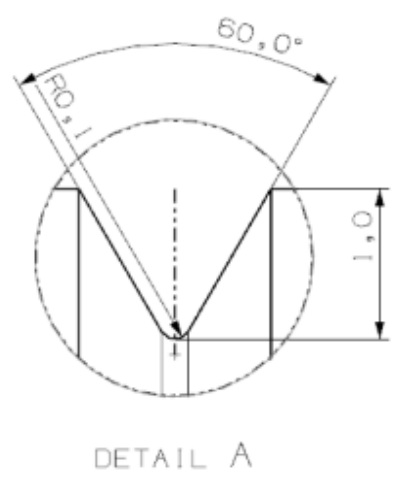

Figure 2. Smooth (a) and notched (b) fatigue test specimens. Detail A shows a closer view of the notch, with its tip radius, $\rho=0.1 \mathrm{~mm}$. All dimensions are in $\mathrm{mm}$.

Table 1. Specimen chemical composition

\begin{tabular}{cccccccc}
\hline Element & $\mathrm{Fe}$ & $\mathrm{Cr}$ & $\mathrm{Mn}$ & $\mathrm{C}$ & $\mathrm{Si}$ & $\mathrm{Mo}$ & $\mathrm{S}$ \\
\hline $\mathrm{wt} \%$ & 95.52 & 1.90 & 1.50 & 0.40 & 0.40 & 0.20 & 0.08 \\
\hline
\end{tabular}

In the manufacturing process, the sheet was cut along the longitudinal axis and rounded to the rough dimension as per Figure 2. Following the rough turning, the specimen was sent for fine ground for a good surface finish. For notch fatigue specimens, a notch was then machined at the centre of the specimen as shown in Figure 2b. Because the supplied material was in the tempered and hardened condition, no further heat treatment was needed.

\subsection{Fretting Ring Calibration}

The fretting fatigue test was conducted through the use of a steel ring assembly designed to exert and sustain the normal force needed to create the clamping load as shown in Figure 3. Strain gauges in the formation of a Wheatstone bridge circuit were installed on the sides of the ring to measure any deflection. The Wheatstone bridge circuit compensates for any deflection change due to temperature 
or other environmental variables that may occur even though all experimental conditions were done at room temperature. The pressure created by the contact pads is then expected to induce fretting from the contact area and its small displacements with the cyclically loaded specimen. Each pad has two contact surfaces, as detailed in Figure 4. The pad span which is the distance between two contact surfaces was chosen to be $10 \mathrm{~mm}$. The pads were made of the M200, the same material as the round bar specimens, thus wear between similar materials can be observed.

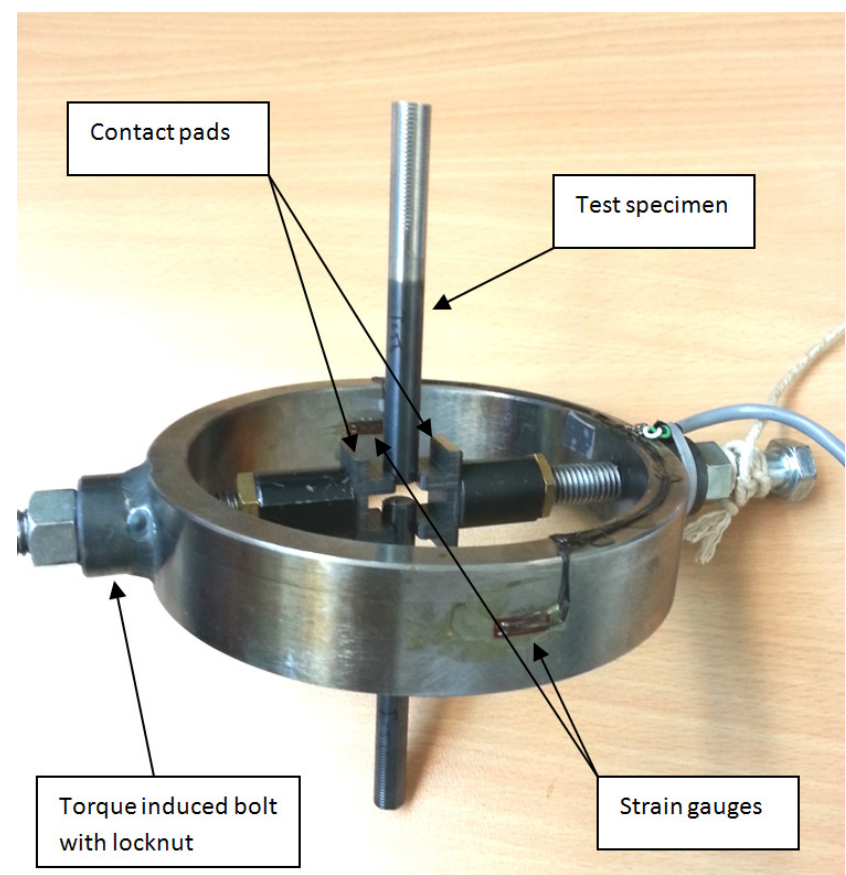

Figure 3. Steel ring assembly with strain gauges used for normal load to induce fretting fatigue

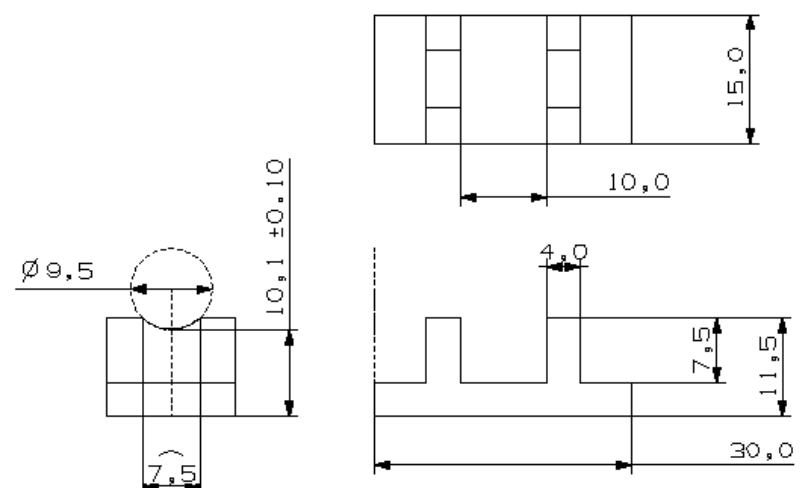

Figure 4. Contact pads used for transmitting the contact pressure. All dimensions in $\mathrm{mm}$.

The alternating stress levels used in the fretting fatigue tests were calculated to ensure that it gives the most fretting damage as reported by Field and Waters [15] to be between 8 and $14 \mu \mathrm{m}$. This was done using the $S=\sigma_{a} x / E$ equation $[16,17]$ which estimates the nominal range of slip, S. Other variables in the equation include the applied stress amplitude, $\sigma_{\mathrm{a}}$ the mean pad span, $x$ and the Young's modulus, E.

An experimental standardisation of the normal forces exerted onto the fatigue specimens was conducted for calibration purposes. Calibration works were then done by firstly exerting a known force onto the steel ring, which would give an output voltage difference read from the strain gage. This change in voltage against a known force was then recorded as shown in Figure 5. Three readings from the same point was done and averaged to compensate for any human and/or experimental error.

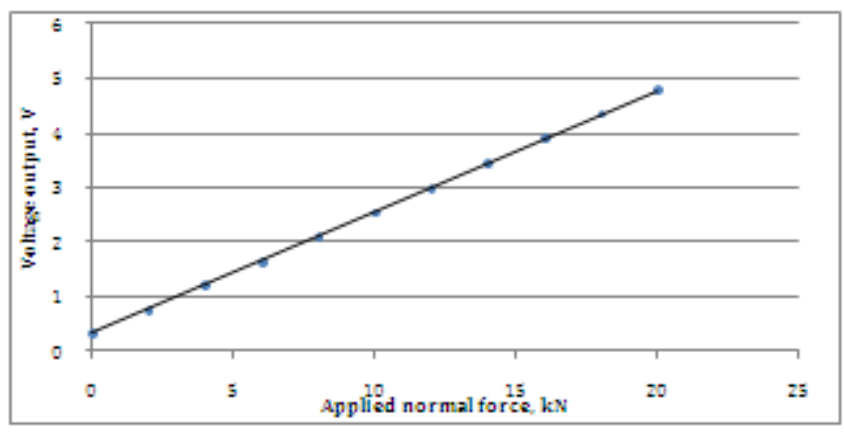

Figure 5. Calibration plot of applied normal force vs output voltage

A sample fatigue specimen would then be attached to the steel ring as per Figure 3 and bolt tightened to a known torque. This bolt tightening would be the proponent that induces the normal force to the specimen through the ring. Again, the output voltage from the torque tightened steel ring would be recorded and converted to force, thus giving the force value for each torque level as shown in Figure 6. Ultimately, no plasticity was observed within the experimental limits. Thus, in this work, two torque tightening levels were selected at $20 \mathrm{Nm}$ and $50 \mathrm{Nm}$.

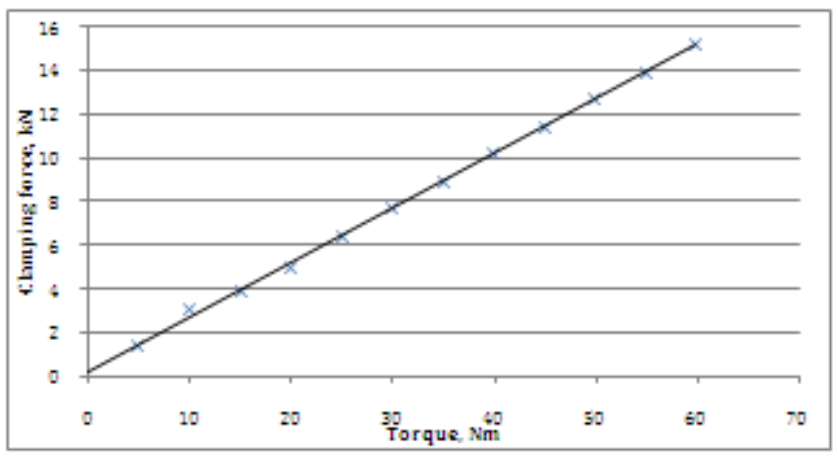

Figure 6. Calibration plot of Torque vs Normal force

\section{Concerning Stress Raisers}

As the objective of this experiment is to study the effect of different 'stress raisers' on fatigue life, an experimental analysis utilizing fatigue sensitivity would need to be done. Therefore, the notch sensitivity, $q_{n}$ and a notch-like sensitivity, $q_{f}$ caused by fretting induced contacts was 
established. A numerical study on the stress distribution of the notched specimen with normal contact was also done.

\subsection{Notch Sensitivity, $q_{n}$}

Three different approaches were employed in determining the notch sensitivity of the specimen, $q_{n}$. These include two different empirical methods using (1) Peterson's constant, $\alpha$, and (2) Neuber's constant, $\beta$, as well as (3) an experimental method by obtaining the fatigue limit at $10^{7}$ cycles from the plotted $S-N$ curves. The equations used for the two empirical methods are represented below [18], while calculations, comparisons, and discussions on the experimentally determined notch sensitivity is reported in section 4.2.

$$
\begin{array}{ll}
\mathrm{q}=\frac{1}{1+\frac{\alpha}{\rho}} & \text { (Peterson) } \\
\mathrm{q}=\frac{1}{1+\sqrt{\frac{\beta}{\rho}}} & \text { (Neuber) }
\end{array}
$$

Both empirical constants were calculated within a few percent accuracy by the fitted expressions (for steel) [18]:

$\log \alpha=2.654 \times 10^{-7} \sigma_{\mathrm{u}}^{2}-1.309 \times 10^{-3} \sigma_{\mathrm{u}}+0.01103(4)$

$\alpha($ in $\mathrm{mm})=10^{\log \alpha} \quad\left(345 \leq \sigma_{\mathrm{u}} \leq 2070 \mathrm{MPa}\right)$

and,

$$
\begin{gathered}
\log \beta=-1.079 \times 10^{-9} \sigma_{\mathrm{u}}^{3}+2.740 \times 10^{-6} \sigma_{\mathrm{u}}^{2}-3.740 \times \\
10^{-3} \sigma_{\mathrm{u}}+0.6404 \\
\beta(\text { in mm })=10^{\log \beta}\left(345 \leq \sigma_{\mathrm{u}} \leq 1725 \mathrm{MPa}\right)
\end{gathered}
$$

Where $\sigma_{\mathrm{u}}$ represents the ultimate tensile strength (in MPa) determined from the tensile tests done in previous work to be $\sigma_{\mathrm{u}}=1081.3 \mathrm{MPa}$. Also as shown in Figure 2b, the tip radius was, $\rho=0.1 \mathrm{~mm}$, while the theoretical stress concentration factor, $k_{t}$, was determined from Peterson's stress concentration factors [1] to be $k_{t}=4.71$. Fatigue notch factor, $k_{f}$ could also be calculated from the empirical estimates by using the following equations:

$$
\begin{aligned}
\mathrm{k}_{\mathrm{f}} & =1+\frac{\mathrm{k}_{\mathrm{t}}-1}{1+\frac{\alpha}{\rho}} \text { (Peterson) } \\
\mathrm{k}_{\mathrm{f}} & =1+\frac{\mathrm{k}_{\mathrm{t}}-1}{1+\sqrt{\frac{\beta}{\rho}}} \text { (Neuber) }
\end{aligned}
$$

\subsection{Fretting Notch-like Sensitivity, $q_{f}$}

The term 'notch-like' is used since the effect of fretting in fatigue can be likened to that of a mechanical notch as concentrated stresses can be found at the edge of the contact region much like a notch tip [9-14]. Significant fretting problems have been seen to be greatly influenced by two mechanical parameters; (a) frictional force, and (b) contact pressure. The product of the two parameters promoted by oscillatory movement on a contact surface results in alternating shear stress which is key in initiating fretting fatigue cracks. From this, Nishioka and Hirakawa $[19,20]$ derived an equation to determine the fretting fatigue limit, $\sigma_{\mathrm{wf}}$ as

$$
\sigma_{\mathrm{wf}}=\sigma_{\mathrm{w} 0}-4 \mu \mathrm{p}_{0}
$$

Where $\sigma_{\mathrm{w} 0}$ is the fatigue limit at $10^{7}$ cycles without fretting, and $4 \mu \mathrm{p}_{0}$ represents the fretting parameters exerted by the four contact pads; $\mu$ being the friction coefficient and $p_{0}$ as the contact pressure.

However, a critical observation made from this expression is that it assumes an increase in fatigue strength would result to an increase in fretting fatigue strength, which has not necessarily been the case observed experimentally.

Thus a modified equation by Wharton et al [21] was developed which incorporates a notch-like sensitivity factor, $q_{f}$

$$
\mathrm{q}_{\mathrm{f}}=\frac{\mathrm{k}_{\mathrm{f}}-1}{\mathrm{k}_{\mathrm{t}}-1}
$$

where

$$
\mathrm{k}_{\mathrm{f}}=\frac{\sigma_{\mathrm{w} 0}}{\sigma_{\mathrm{wf}}} \text { and } \mathrm{k}_{\mathrm{t}}=\frac{\sigma_{\mathrm{f}}}{\sigma_{\mathrm{a}}}
$$

Definitions of the fatigue notch factor, $k_{f}$ and stress concentration factor, $k_{t}$ differ slightly to adapt to the context of fretting fatigue where $k_{f}$ is the ratio between the fatigue limit at $10^{7}$ cycles without fretting, $\sigma_{\mathrm{w} 0}$ and $10^{7}$ cycles with fretting, $\sigma_{\mathrm{wf}}$. As for $k_{t}, \sigma_{a}$ is the stress amplitude inflicted on the fatigue specimen while $\sigma_{f}$ is the fretting fatigue stress amplitude, defined by the regular amplitude stress and includes the effect of friction coefficient and contact pressure (fretting parameter). Therefore

$$
\sigma_{\mathrm{f}}=\sigma_{\mathrm{a}}+4 \mu \mathrm{P}_{0}
$$

Modifying equation (10) to incorporate the notch-like sensitivity factor, $q_{f}$ would give

$$
\sigma_{\mathrm{wf}}=\sigma_{\mathrm{w} 0}-\mathrm{q}_{\mathrm{f}} 4 \mu \mathrm{p}_{0}
$$

With this modified equation, the sensitivity factor, $q_{f}$ accounts for the feature whereby materials with high plain fatigue strength does not necessarily have also have a high fretting fatigue strength.

\subsection{Finite Element Stress Distribution}

As mentioned before, the inclusion of contact pads exerting a normal clamping load onto the specimen during fatigue cycles would induce fretting from the small displacements of the contact. However, another effect that is also evident from the added contact loads is a biaxial stress distribution. This is of great concern especially due to its ability to have an effect on notched geometries with high stress concentration factors.

Thus, numerical analyses on the geometry of both smooth and notched specimens were done to determine its stress distribution when inflicted with clamping pressure, at varying magnitudes.

A 3D model of the fatigue notched specimen using tetrahedral shaped elements was generated using ABAQUS 6.11 finite element package. Because both the geometry and 
loading are symmetric with respect to two Cartesian planes, only one-fourth of the specimen was modeled, and thus symmetric displacement boundary conditions were defined for the nodes on the planes of symmetry. The size of the elements was refined several times in order to obtain a converged solution (element independent result).

An elastic-isotropic material model was used to represent the AISI P20 stress-strain behaviour. Elastic Modulus, E and Poisson's ratio, $v$ used in the model were 202.04 GPa and 0.3, respectively. Numerical analyses were carried out by applying an axial static tensile load of $71.5 \mathrm{MPa}$ and 182.6 $\mathrm{MPa}$ at the clamped region (Figure 7), representing the 20 $\mathrm{Nm}$ and $50 \mathrm{Nm}$ torque tightening, respectively.



Figure 7. Cross section of the notched $3 \mathrm{D}$ model. Stress distributions along $\mathrm{z}$ axis (cross section 1), $\mathrm{x}$ axis (cross section 2), and $\mathrm{y}$ axis (top plane) were recorded respectively.


Figure 8. Distribution of von mises stress for both (a) smooth and (b) notched 3D model along the z-axis (cross section 1) from the free edge. Plotted are stress distributions at two different contact torque levels of $20 \mathrm{Nm}$ and $50 \mathrm{Nm}$, as per experimental values.
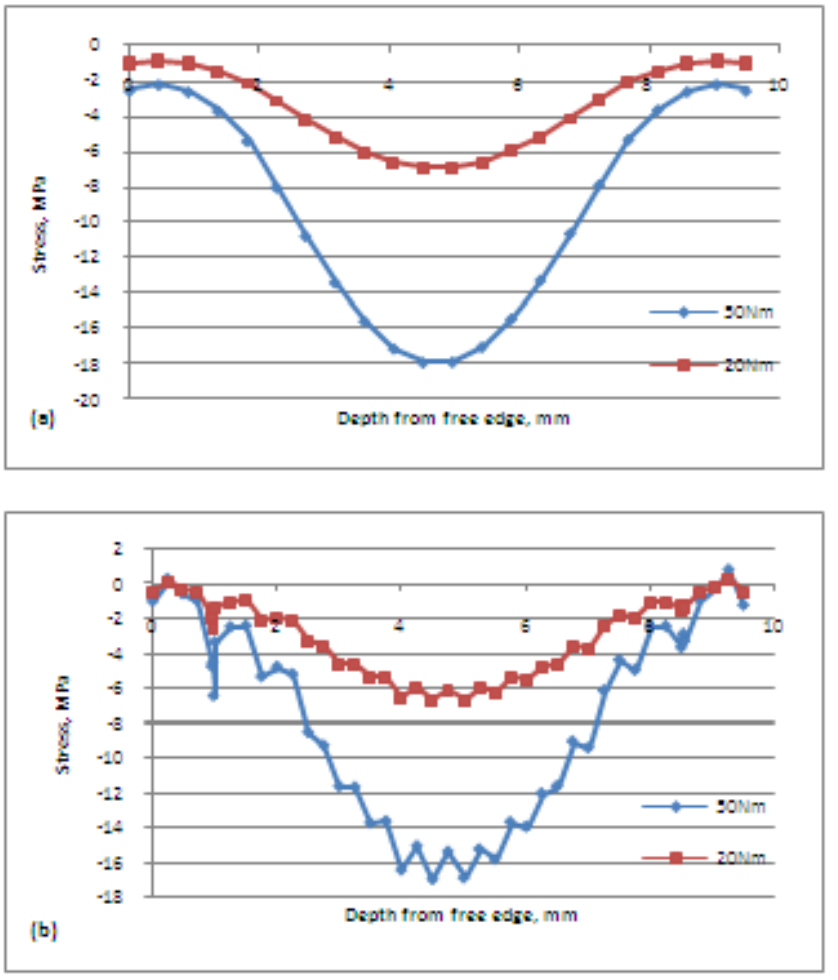

Figure 9. Distribution of von mises stress for both (a) smooth and (b) notched 3D model along the $\mathrm{x}$-axis (cross section 2) from the free edge. Plotted are stress distributions at two different contact torque levels of $20 \mathrm{Nm}$ and $50 \mathrm{Nm}$, as per experimental values.

Evident from Figures 8 and 9 above that an increase in contact torque increases the stress levels at the notch tip and free edge for the notched and smooth specimens, respectively. Compressive stresses are found in the longitudinal direction along the $\mathrm{x}$-axis (Figure 9) which suggests a reduction in the total amount of resultant stress from the applied tensile external loads. The compressive stress increases and peaks mid section of the 3D model in both $\mathrm{z}$-axis (Figure 8) and x-axis (Figure 9). It is also apparent from comparing between Figures 8 and 9, that the region of highest stress that is located at the notch tip or free edge along the z-axis for the notched or smooth specimens, respectively. This could then bring forth the assumption that the specimen failure will occur from said region as the region of highest stress concentration.

However, it is important to note that the numerical work done only considers the effect of normal clamping pressure on the stress distribution and discounts the fretting (oscillatory sliding displacements) itself which could induce various tribologically detrimental effects $[9,22]$.

Another observation from the finite element stress distribution worth mentioning is that within the magnitude of applied contact pressure, all stresses and strains remained in the elastic region.

Along the top plane, longitudinal stress distributions were also plotted, as can be seen in Figure 10. Negative stresses are observed all through the contact pressure region. The highest stress distribution in this longitudinal direction is 
seen to be at the notch tip (excited by the contact pressure) for the notched model. The smooth model on the other hand has its highest longitudinal stress at the edge of the contact area. A similar pattern can be seen for the notched model's contact edge, however a higher amount is observed at the notch tip. These high stress regions are obviously regions of interest as heightened stresses are regions superseding the crack threshold stress, thus being region where cracks are most likely to initiate.
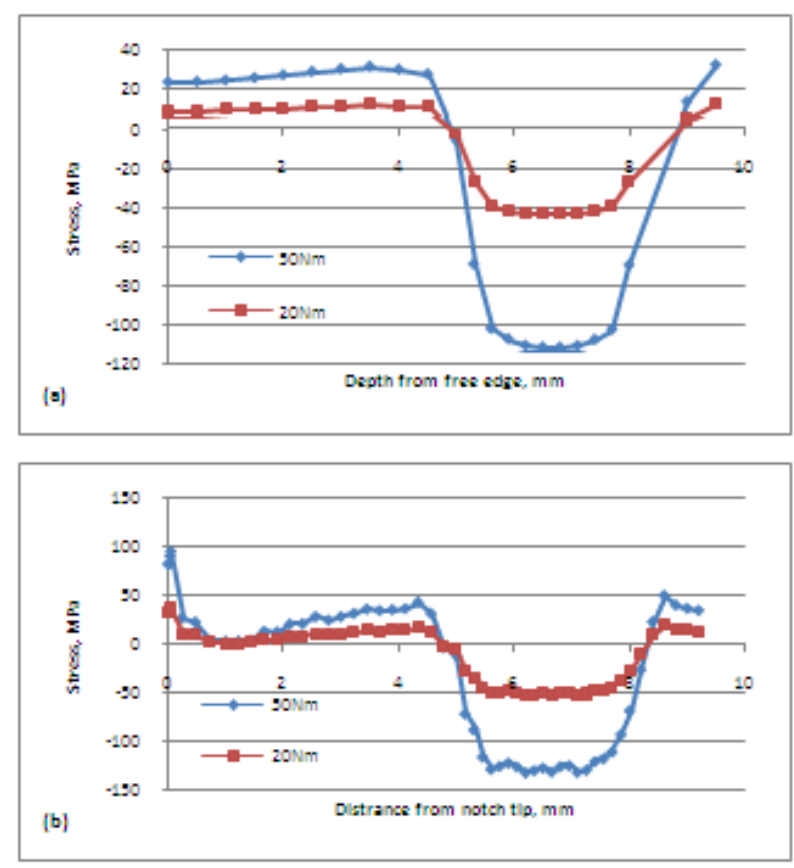

Figure 10. Distribution of von mises stress for both (a) smooth and (b) notched 3D model along the y-axis from the mid symmettrical section or notch tip, respectively. Plotted are stress distributions at two different contact torque levels of $20 \mathrm{Nm}$ and $50 \mathrm{Nm}$, as per experimental values.

\section{Fatigue Results and Discussions}

\section{1. $S$ - $N$ Curves}

The S-N curves depicted in Figure 11 above compares the benchmark smooth (un-notched) fatigue specimens with two different stress raisers and the combination of the two, with Figure 11a showing a percentage reduction in fatigue life of up to $99.8 \%$ due to the notch and Figure $11 \mathrm{~b}$ showing a percentage reduction in fatigue life of up to $96.2 \%$ and $96.9 \%$ due to fretting fatigue at torque levels $20 \mathrm{Nm}$ and $50 \mathrm{Nm}$ respectively. Figure $11 \mathrm{c}$ on the other hand shows the reduction in fatigue life due to the combination of notch and fretting. A main graph plotting all fatigue conditions as well as its percentage reduction in fatigue life compared to the smooth (un-notched) specimens can be seen in Figure 12.

The notch fatigue case in Figure 11a is an obvious one which shows significant reductions in fatigue lives due to the stress raised from the geometrical discontinuity.

With regards to fretting fatigue in Figure $11 \mathrm{~b}$, a slight reduction in fatigue life can be seen with an increase of clamping force especially at high stress levels. However, the difference in fatigue life is not seen to differ significantly at lower alternating stress levels.


Figure 11. S-N curve of smooth (un-notched) fatigue tests specimen compared with (a) notched, (b) fretting fatigue, and (c) combination of notch and fretting stress raisers respectively.

It is interesting to observe that the combination of notch and fretting fatigue (Figure 11c) however does not show any further reduction when compared to the notched only specimen as can be seen in Figure 12. Although fretting fatigue on its own has significant detrimental effects as can be seen by the significant wear observed in Section 5 pertaining fractographic observation as well as from the results of normal clamping from the finite element results (Section 3.3), in a situation with a combination of both notches and fretting fatigue, the notch effect was still found to be the source of fatigue cracks. This means that in this 
study, notches as stress raisers are seen to be the dominant mode of failure and as no further reductions in fatigue life was found, it can also be asserted that the combination of two failure modes does not increase the probability of failure.

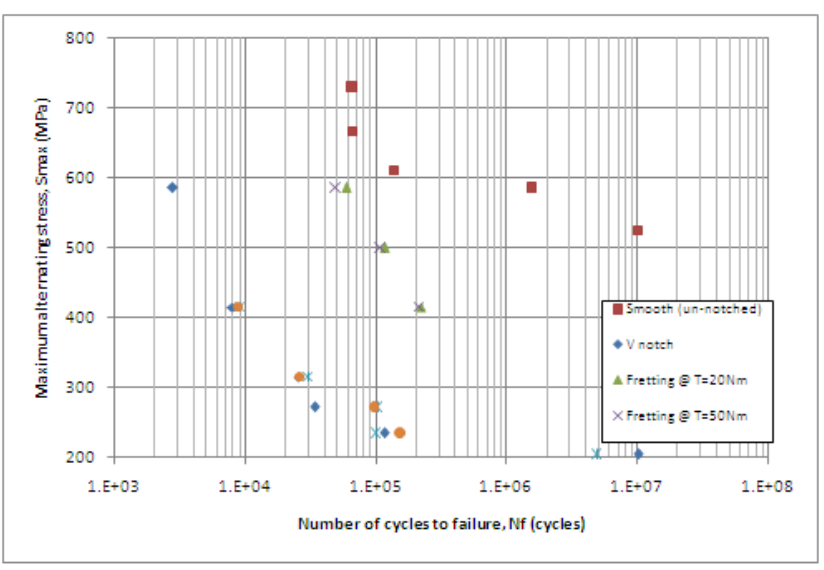

Figure 12. S-N curves showing reduction in fatigue lives due to fretting $(\mathrm{T}=20 \mathrm{Nm}$ and $50 \mathrm{Nm})$, notch and a combination of both fretting and notch

Table 2. Notch sensitivity, $q_{n}$ and percentage difference from the experimental result

\begin{tabular}{|c|c|c|c|c|}
\hline Method & $\begin{array}{c}\text { Stress } \\
\text { concentration } \\
\text { factor, } k_{t}\end{array}$ & $\begin{array}{c}\text { Fatigue } \\
\text { notch } \\
\text { factor, } \\
k_{f}\end{array}$ & $\begin{array}{c}\text { Notch } \\
\text { sensitivity, } \\
q_{n}\end{array}$ & $\begin{array}{c}\text { Difference } \\
\text { from } \\
\text { experimental } \\
\text { result }\end{array}$ \\
\hline Experimental & 4.71 & 2.56 & 0.42 & - \\
\hline $\begin{array}{c}\text { Peterson's }(\alpha \\
=0.0805 \\
\mathrm{~mm})\end{array}$ & 4.71 & 3.06 & 0.53 & $26.2 \%$ \\
\hline $\begin{array}{c}\text { Neuber's }(\beta \\
=0.0273 \\
\mathrm{~mm})\end{array}$ & 4.71 & 3.43 & 0.65 & $54.8 \%$ \\
\hline
\end{tabular}

Table 3. Experimentally determined notch-like sensitivity, $q_{f}$

\begin{tabular}{|c|c|c|c|}
\hline $\begin{array}{c}\text { Torque } \\
\text { level }\end{array}$ & $\begin{array}{c}\text { Stress } \\
\text { concentration } \\
\text { factor, kt }\end{array}$ & $\begin{array}{c}\text { Fatigue } \\
\text { reduction } \\
\text { factor, kf }\end{array}$ & $\begin{array}{c}\text { Notch-like } \\
\text { sensitivity, qf }\end{array}$ \\
\hline $20 \mathrm{Nm}$ & 1.58 & 3.05 & 3.52 \\
\hline $50 \mathrm{Nm}$ & 1.74 & 3.44 & 3.28 \\
\hline
\end{tabular}

Table 4. Experimentally determined notch-like sensitivity, $q_{f}$

\begin{tabular}{|c|c|c|c|}
\hline $\begin{array}{c}\text { Torque } \\
\text { level }\end{array}$ & $\begin{array}{c}\text { Stress } \\
\text { concentration } \\
\text { factor, kt }\end{array}$ & $\begin{array}{c}\text { Fatigue } \\
\text { reduction } \\
\text { factor, kf }\end{array}$ & $\begin{array}{c}\text { Notch-like } \\
\text { sensitivity, qf }\end{array}$ \\
\hline $20 \mathrm{Nm}$ & 1.58 & 3.05 & 3.52 \\
\hline $50 \mathrm{Nm}$ & 1.74 & 3.44 & 3.28 \\
\hline
\end{tabular}

\subsection{Notch and Notch-like Sensitivity}

As previously reported in Section 3.1, two empirical methods of estimating the notch sensitivity, $q_{n}$ were done to validate the experimental results. From the $S-N$ curves plotted in Figure 11a and again in Figure 12 of the v-notch specimen, an experimentally determined notch sensitivity, $q_{n}$ was calculated and summarized in Table 2. It was found that the calculated result for the notch sensitivity, $q_{n}$ is within the range of 0.42 to 0.65 amongst all three approaches.

As for the notch-like sensitivity, $q_{f}$ due to fretting fatigue, an experimentally determined value was obtained from the S-N curves plotted in Figure 11b and again in Figure 12. A summary of the calculated values can be seen in Table 3. A similar assumption to Wharton et al [21] was made with regards to the friction coefficient, $\mu$. This was that since it is well known that a rapid increase in friction coefficient close to 1 followed by an approximately constant phase [16] can be observed when under fretting type cyclic loading, thus, the friction coefficient was chosen to be 0.9 in equation (13) to take into account the average value throughout the experiment. Also, based on the assumption made by Wharton et al [21] for equation (13) with regards to stress concentration factor, $k_{t}$, it seems that the ratio of stress raised due to friction and contact pressure is only 1.58 and 1.74 for torque levels $20 \mathrm{Nm}$ and $50 \mathrm{Nm}$, respectively. This does not reflect similarly when the reduction factor, $k_{f}$ is determined from the experiment which results in the notch-like sensitivity to have a significantly higher value as can be seen from Table 4. Such an observation is not a surprise as it has been reported before in cases where material factors dominate, such as in the case of some quenched and tempered steels, $k_{f}$ may sometimes be greater than $k_{t}[23$, 24]. Therefore, it simply means that the fretting effect as a stress raiser must also be significantly affected by other material factors or surface conditions [6]. As for the comparison in fretting notch-like sensitivity value, $q_{f}$ the higher value observed for the $20 \mathrm{Nm}$ torque level (3.52) compared to the $50 \mathrm{Nm}$ torque level (3.28) simply meant that the $k_{f} k_{t}$ ratio for the $20 \mathrm{Nm}$ level was higher as the difference in fatigue life did not differ significantly especially at lower alternating stress levels (Figure 11b).

A notch or notch-like sensitivity for the case of combined notch and fretting fatigue could not be done as a method of mathematically superimposing the two different stress raisers to represent a single theoretical stress concentration factor was not explored completely. However, as mentioned in section 4.1 with regards to the dominating mode of failure; it seems that the combination of the two stress raisers results in failure at the notch regardless of the alternating stress levels. This gives opportunity for further work comparing the performance of the two stress raisers with varying notch severity and contact pressures in terms of its fatigue sensitivity.

\section{Fractographic Observations}

Figure 13 evidently shows the crack origin from fretting wear at the edge of the contact region of a failed fretting fatigue test specimen. Figure 14 however shows a notch and fretting fatigue specimen which has a significantly damaged surface due to the fretting effect but the crack origin was found to have occurred at the notch tip. This asserts that 
although the surface experienced fretting wear to an extent, the combined increase in stress concentration at the notch tip (as shown earlier by the finite element stress distribution) was found to be the critical mode of failure, conforming with the results observed from the S-N curves (Figure 12).
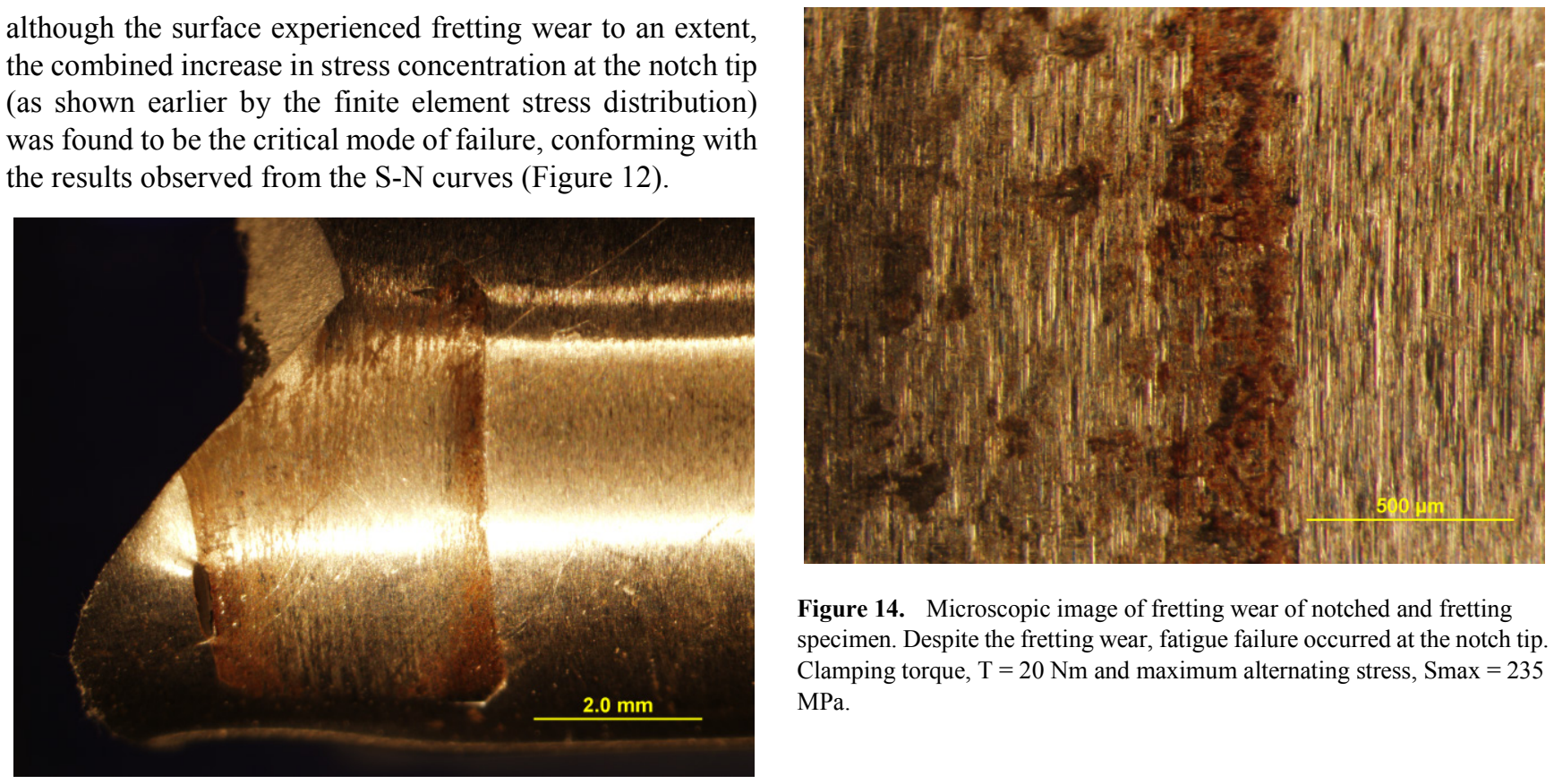

Figure 14. Microscopic image of fretting wear of notched and fretting specimen. Despite the fretting wear, fatigue failure occurred at the notch tip. Clamping torque, $\mathrm{T}=20 \mathrm{Nm}$ and maximum alternating stress, $\operatorname{Smax}=235$ MPa.

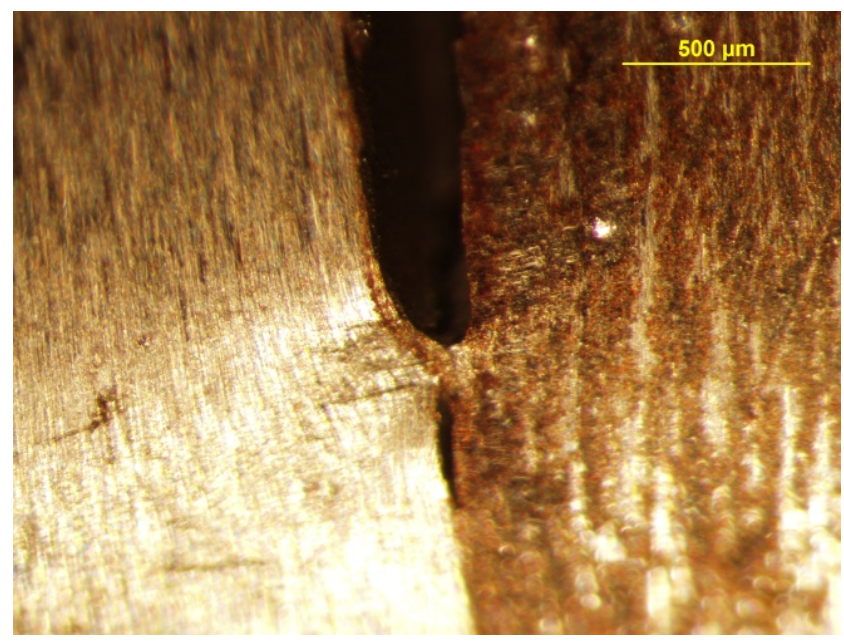

\section{Conclusions}

In this work, stress raisers were applied on fatigue specimens to study its performance in fatigue sensitivity. First, finite element analyses on the effect of clamping pressure on a notched geometry resulted in a further increase in stress concentration at the notch tip for this specific geometry. This prompted an indication that the relationship between the two stress raisers could intensify its susceptibility for fatigue failure. However, results from the fatigue tests revealed that there was no significant difference in fatigue life between the notched only and the combined notch and fretting fatigue.

Several methods in measuring the notch sensitivity, $q_{n}$ revealed that the notch geometry gave is within the range of 0.42 to 0.65 . Similarly, a notch-like sensitivity, $q_{f}$ was calculated from the fretting fatigue results using a method by

Figure 13. Microscopic image of fretting fatigue crack of smooth (un-notched) specimen occurring at the edge of the contact region. Clamping torque, $\mathrm{T}=20 \mathrm{Nm}$ and Maximum alternating stress, $\operatorname{Smax}=585$ $\mathrm{MPa}$.

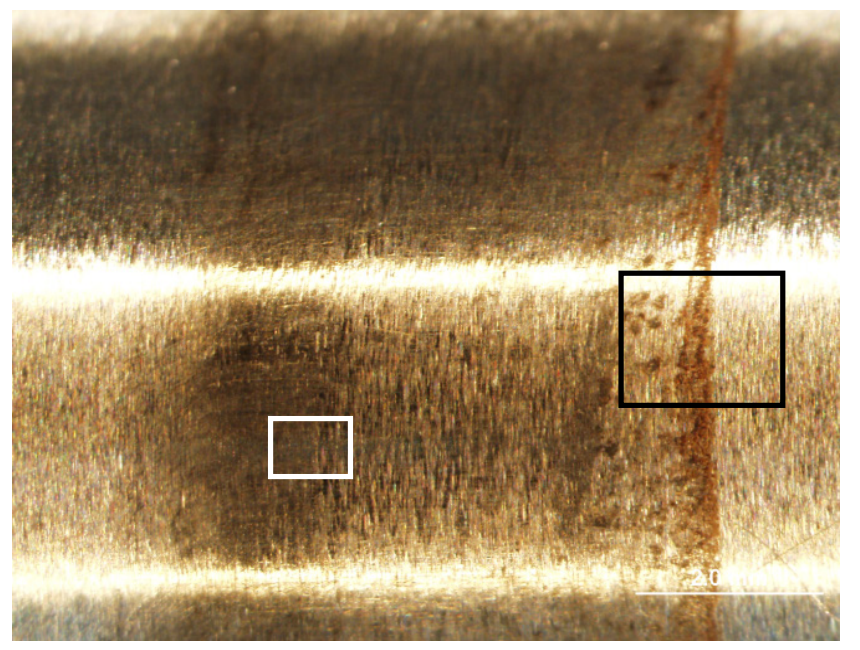
Wharton et al. and was found to be 3.52 and 3.28 at torque tightening levels $20 \mathrm{Nm}$ and $50 \mathrm{Nm}$ respectively. It was found that the stress concentration factor, $k_{t}$ in the case of the ratio of stress raised due to frictional forces and clamping pressure was very conservative in its value and did not correlate well with the experimentally determined reduction factor, $k_{f}$. This obviously resulted in a very high notch-like sensitivity, $q_{f}$. The fact that a higher value is observed for the $20 \mathrm{Nm}$ torque level compared to the $50 \mathrm{Nm}$ torque level simply meant that the $k_{f} / k_{t}$ ratio for the $20 \mathrm{Nm}$ level was higher as the difference in fatigue life did not differ significantly especially at lower alternating stress levels.

An opportunity for further work can be found in exploring a method to mathematically superimpose the stress concentration factor, $k_{t}$ in the case of the combined notch and fretting fatigue. This would enable researchers and designers to better draw parallels between stresses raised due to geometrical discontinuities (notches) and contact displacements (wear). 
Finally, fractorgraphic analysis revealed that significant fretting wear was found for both fretting fatigue specimens and the combined notch and fretting fatigue. Fatigue cracks however were found to originate from the notch tip for the combined notch and fretting fatigue at all alternating stress levels.

\section{REFERENCES}

[1] Pilkey, W.D. and D.F. Pilkey, Peterson's Stress Concentratio n Factors. 3rd Edition ed. 2007, New Jersey: Jown Wiley \& Sons, Inc.

[2] Fretting Fatigue, ed. R.B. Waterhouse. 1981, Essex: Applied Science Publishers Ltd.

[3] Majzoobi, G.H., et al., Modification of fretting fatigue behavior of AL7075-T6 alloy by the application of titanium coating using IBED technique and shot peening. Tribology International, 2009. 42(1): p. 121-129.

[4] $\mathrm{Fu}, \mathrm{Y}$., et al., Improvement in fretting wear and fatigue resistance of Ti-6Al-4V by application of several surface treatments and coatings. Surface and Coatings Technology, 1998. 106(2-3): p. 193-197.

[5] Vadiraj, A. and M. Kamaraj, Characterization of fretting fatigue damage of PVD TiN coated biomedical titanium alloys. Surface and Coatings Technology, 2006. 200(14-15): p. $4538-4542$.

[6] Fu, Y., J. Wei, and A.W. Batchelor, Some considerations on the mitigation of fretting damage by the application of surface-modification technologies. Journal of Materials Processing Technology, 2000. 99(1): p. 231-245.

[7] Ben Cheikh Larbi, A. and B. Tlili, Fretting wear of multilayered PVD TiAlCN/TiAlN/TiAl on AISI 4140 steel. Surface and Coatings Technology, 2006. 201(3-4): p. 1511-1518.

[8] Oskouei, R.H., R.N. Ibrahim, and M.R. Barati, An experimental study on the characteristics and delamination of TiN coatings deposited on Al 7075-T6 under fatigue cycling. Thin Solid Films. 526(0): p. 155-162.

[9] Nowell, D. and D. Dini, Stress gradient effects in fretting fatigue. Tribology International, 2003. 36(2): p. 71-78.

[10] Nowell, D., D. Dini, and D.A. Hills, Recent developments in the understanding of fretting fatigue. Engineering Fracture Mechanics, 2006. 73(2): p. 207-222.

[11] Giannakopoulos, A.E., T.C. Lindley, and S. Suresh, Aspects of equivalence between contact mechanics and fracture mechanics: theoretical connections and a life-prediction methodology for fretting-fatigue. Acta Materialia, 1998.
46(9): p. 2955-2968.

[12] Giannakopoulos, Suresh, and Chenut, Similarities of stress concentrations in contact at round punches and fatigue at notches: implications to fretting fatigue crack initiation. Fatigue \& Fracture of Engineering Materials \& Structures, 2000. 23(7): p. 561-571.

[13] Ciavarella, M. and G. Macina, New results for the fretting-induced stress concentration on Hertzian and flat rounded contacts. International Journal of Mechanical Sciences, 2003. 45(3): p. 449-467.

[14] Ciavarella, M., A 'crack-like' notch analogue for a safe-life fretting fatigue design methodology. Fatigue \& Fracture of Engineering Materials \& Structures, 2003. 26(12): p. 1159-1170.

[15] Field, J.E. and D.M. Waters, Fretting fatigue strength of En26 steel: Effect of mean stress, slip amplitude and clamping conditions, in National Engineering Laboratory Report No. 275. 1967.

[16] Lindley, T.C., Fretting fatigue in engineering alloys. International Journal of Fatigue, 1997. 19(93): p. 39-49.

[17] Lindley, T.C., et al., Fretting Fatigue, in Encyclopedia of Materials: Science and Technology (Second Edition). 2001, Elsevier: Oxford. p. 3347-3351.

[18] Dowling, N.E., Stress-Based Approach to Fatigue: Notched Members, in Mechanical Behaviour of Materials Engineering Methods for Deformation, Fracture and Fatigue, H. Stark, Editor. 2013, PEARSON: New Jersey. p. 479.

[19] Nishioka, K. and K. Hirakawa, Fundamental investigation of fretting fatigue: Part 5, the effect of relative slip. Bulletin of Japan Society of Mechanical Engineers, 1969. 12(52): p. 692.

[20] Nishioka, K. and K. Hirakawa, Fundamental Investigation of fretting fatigue: Part 6, Effect of contact pressure and hardness of materials. Bulletin of Japan Society of Mechanical Engineers, 1972. 15(80): p. 135.

[21] Wharton, M.H., et al., The effect of different contact materials on the fretting fatigue strength of an aluminium alloy. Wear, 1973. 26(2): p. 253-260.

[22] Hattori, T., M. Nakamura, and T. Watanabe, Simulation of fretting-fatigue life by using stress-singularity parameters and fracture mechanics. Tribology International, 2003. 36(2): p. 87-97.

[23] Yen, C.S. and T.J. Dolan, A critical review of the criteria for notch-sensitivity in fatigue of metals. University of Illinois Bulletin Experiment station, 1952. 398.

[24] Yen, C.S. and T.J. Dolan, Some aspects of the effects of Metallurgical Structure on the Fatigue Strength and notch-sensitivity of steel. American Society for Testing Materials 1948. 48: p. 664. 